\title{
Anaesthesia for tracheal resection: report of 17 cases
}

Lennart Magnusson MD, Florian J.W. Lang MD, * Philippe Monnier MD, ${ }^{*}$ Patrick Ravussin MD

Purpose: Laryngo-tracheal stenosis remains a major complication after prolonged intubation or tracheostomy. Surgical resection with end-to-end anastomosis carries the best long term prognosis. For the anaesthetist, however, this procedure represents a most challenging situation.

Methods: Since 1993, we have used high frequency jet ventilation (HFM) for tracheal resection. This paper describes the technique and the results of our series including 7 adults and 10 children.

Results: There were no adverse haemodynamic or ventilatory consequences due to HFJV. Oxygenation was well maintained during the HFJV period. Sixteen of the 17 patients had a good outcome. Despite the good result of the resection-anastomosis, one child still suffers from an associated posterior glottic stenosis.

Conclusion : Since the introduction of HFN for surgery of tracheal stenosis in our institution no complication of this ventilatory technique has occured. It reduces the manipulation of the ventilation system and the period of apnea, thus decreasing the risk of hypoxaemia. The good access to the surgical field contributes to the success of resection-anastomoses in laryngo-tracheal stenosis.

Objectif : La sténose laryngo-trachéale constitue une complication majeure de l'intubation prolongée et de la trachéostomie. Sa résection chirurgicale avec anastomose termino-terminale procure le meilleur pronostic à long terme. Cependant, cette l'intervention représente pour l'anesthésiste un défi de taille.

Méthodes : Depuis 1993, nous avons utilisé la ventilation par jet à haute fréquence (VJHF) pour la résection trachéale. Cet article en décrit la technique et nos résultats sur une série de sept adultes et de dix enfants.

Résultats : La VJHF n'a provoqué aucune conséquence hémodynamique ou ventilatoire défavorable. L'oxygénation s'est maintenue pendant la période de VJHF. Seize des 17 patients ont connu une évolution heureuse. Malgré les bons résultats de la résection-anastomose, un enfant est toujours affigé d'une sténose postérieure de la giotte.

Conclusion : Depuis l'introduction dans notre institution de la VJHF pour la chirurgie de la sténose trachéale, nous n'avons déploré aucune complication due à cette technique de ventilation. Elle réduit les manipulations de l'appareil respiratoire et la période d'apnée et ainsi le risque d'hypoxémie. La facilité d'accès au champ opératoire contribue aux succès de la résection et de l'anastomose dans la sténose laryngo-trachéale.

From the Departments of Anaesthesiology and Otorhinolaryngology, Centre Hospitalier Universitaire Vaudois, 1011 Lausanne, Switzerland. Address correspondence to: Dr. L. Magnusson, Department of Anaesthesiology, CHUV, 1011 Lausanne, Switzerland.

Phone: +41-21-314-20-00; Fax: +41-21-314-20-04

Accopted for publication September 28, 1997. 
A CQUIRED laryngo-tracheal stenosis remains a potential major complication of long term intubation. When surgery is feasible, more than $90 \%$ of good long term results may be expected in direct resection and end-to-end anastomosis. ${ }^{1,2}$

Tracheal resection is a particularly challenging situation for the anaesthetist: adequate visualisation of an immobile endotracheal lumen is essential for the surgeon; at the same time adequate gas exchange for the patient must be guaranteed. From 1974 to 1981 , some case reports have described the use of jet ventilation for tracheal resection in children ${ }^{3,4}$ and in adults. ${ }^{5,6}$ Giunta et al. in $1989^{7}$ reported a series of 11 adults patients ventilated with high frequency jet ventilation (HFJV) for tracheal stenosis resection. During the last three years (from 1993 to 1996) we have used HFJV in 17 patients scheduled for laryngo-tracheal resection and direct anastomosis, 10 children and 7 adults.

The aim of this report is to describe the ventilation technique used at our institution for this type of procedure, and to discuss its advantages and drawbacks.

\section{Material and methods}

Premedication consisted of midazolam associated, for the children, with atropine. Anaesthesia induction was achieved with halothane by mask in children and propofol in adults, followed by fentanyl and vecuronium. Conventional intubation was performed after endoscopic dilatation of the stenosis (see Figure 1A): IPPV was instituted with $100 \% \mathrm{O}_{2}$ and anaesthesia maintenance was achieved with propofol, fentanyl and vecuronium as needed.

Once the proximal trachea was opened, the ET was withdrawn until the tip appeared in the operative field. A thread was passed through Murphy's eye by the surgeon (see Figure 1B). A $14 \mathrm{Fr}$ nasal catheter $410 \mathrm{~mm}$ long (ED: $4.7 \mathrm{~mm}$ ) for the adults or a $10 \mathrm{Fr} 400 \mathrm{~mm}$ long (ED: $3.3 \mathrm{~mm}$ ) for the children was then passed through the tube and placed distally in the trachea by the surgeon (see Figure 1C). Once the jet catheter was correctly placed, the ET was further withdrawn out of the operation field. HFJV was then instituted using a AMS-1000 HFJ Ventilator (Acutronic, 8645 Jona, Switzerland). The parameters were" set as follows for adults: rate: 150. $\mathrm{min}^{-1}$; driving pressure: $2-4$ bars, progressively increased to a minute ventilation of $250 \mathrm{ml} \cdot \mathrm{kg}^{-1}$; $\mathrm{Ti}$ /Ttot: 0.3 ; peak inspiratory pressure limit: $30 \mathrm{mbar}$; for children: rate: $40-100 \cdot \mathrm{min}^{-1}$; driving pressure: $0.5-2$ bars; $\mathrm{Ti}$ /Ttot: $0.2-0.4$. The distal part of the trachea was continuously moisted in order to prevent dessication.

Just before tying the last sutures, the ET was pushed down in the trachea over the jet catheter using the leading thread passed through the Murphy's eye. The jet ventilation catheter was withdrawn and the ET repositioned beyond the anastomosis. The cuff of the ET was positioned distally to the anastomosis (see Figures 1D, 1E).

Conventional ventilation was reinstituted until the end of the operation. Most patients were extubated at the end the of the procedure. At one week, three months and one year, all patients underwent a laryngotracheoscopy in order to control the patency of the trachea and to detect any late complications.

All results are expressed as mean $\pm \mathrm{SD}$. Analysis of variance for repeated measurements was used to interpret the variations of the respiratory and the haemodynamic parameters.

Good surgical results were defined as patients who were able to live normally and experience no or only slight dyspnea while exercising. Children should tolerate upper airway infections without stridor.
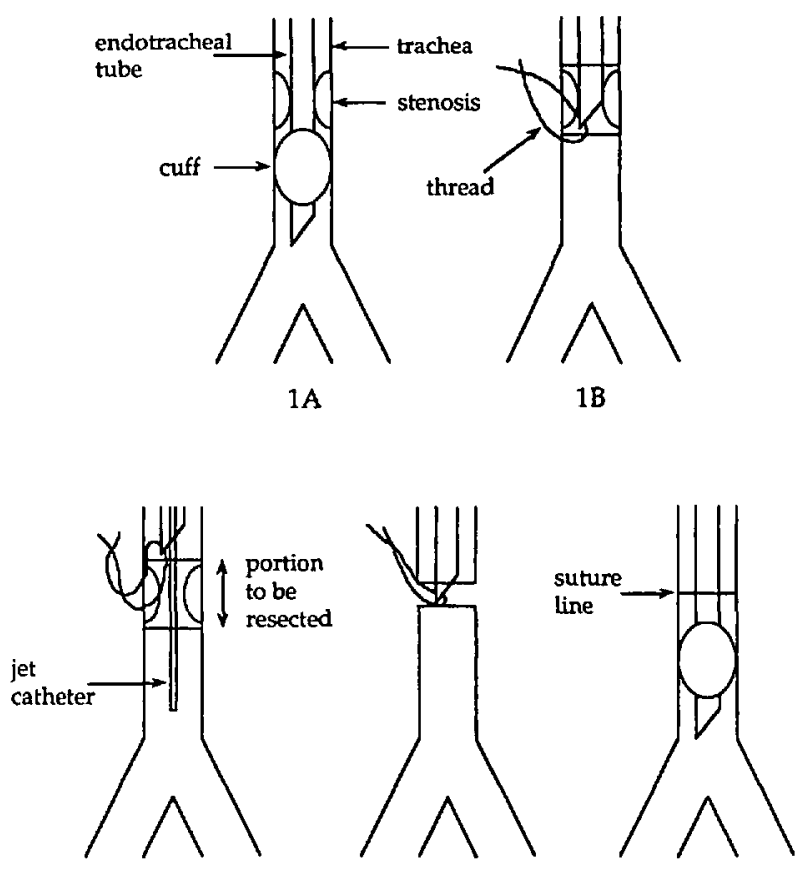

$1 \mathrm{C}$

$1 \mathrm{D}$

$1 \mathrm{E}$

FIGURE 1 Ventilation technique as described in Material and Methods.

1A) intubation, after dilatation of the stenosis; 1B) marking of the ET tube with a thread after the trachea has been opened; 1C) withdrawing of the ET tube and rescetion of the stenosis with HFJV; ID) drawing back of the ET tube just before completion of the anastomosis and placement of the cuff distally to the surure line; $1 \mathrm{E})$ completion of the anastomosis. 


\section{Results}

The demographic and operative data are summarised in Table I.

The $\mathrm{PaO}_{2}$ decreased $10 \mathrm{~min}$ after the start of $\mathrm{HFJV}$ in the paediatric group but remained stable thereafter (Table II). In the adult group ( $n=7$ ) there was no variation in $\mathrm{PaO}_{2} . \mathrm{PaCO}_{2}$ did not vary in the paediatric group but increased in the adult group during HFJV. The haemodynamic parameters (Table II) did not vary during the procedure in both groups.

The surgical results were excellent. All patients were decanulated, 16 out of 17 showed no dyspnea or a slight stridor at intense physical exertion as well as a normal or nearly normal voice. Only one patient still suffers of dyspnea already at moderate physical exertion and of a strong dysphonia, due to an associated posterior laryngeal stenosis.

\section{Discussion}

All sorts of anaesthetic techniques have been described for tracheal resection: spontaneous ventilation throughout the procedure, sterile ET placed directly in the distal trachea, extracorporeal circulation. Many authors ${ }^{7-10}$ have used HFJV for tracheal resection. The advantages of this technique over conventional ventilation include 1) simplification of airway management; 2 ) elimination of the ET from the surgical field; 3 ) adequate control of gas exchange during surgery; 4) immobile surgical field

TABLE I Demographic and operative data

\begin{tabular}{lcc}
\hline & $\begin{array}{c}\text { Paediatric group } \\
\mathrm{n}=10\end{array}$ & $\begin{array}{c}\text { Adult group } \\
\mathrm{n}=7\end{array}$ \\
\hline age (years) & $6 \pm 4$ & $54 \pm 10$ \\
weight $(\mathrm{kg})$ & $19 \pm 9$ & $71 \pm 18$ \\
male/female & $6 / 4$ & $5 / 2$ \\
Duration of surgery (min) & $190 \pm 37$ & $170 \pm 53$ \\
Duration of jet ventilation (min) & $85 \pm 26$ & $45 \pm 17$ \\
\hline
\end{tabular}

mean $\pm S D$ and 5 ) continuous gas flow coming out of the trachea. These advantages are confirmed by our report. Oxygenation of the patients and $\mathrm{CO}_{2}$ removal were adequate. No hypoxaemia occurred, although the $\mathrm{PaO}_{2}$ decreased significantly in the paediatric group being however always above $200 \mathrm{mmHg}$ (Table II). Modest hypercarbia was seen in the adult patients during HFJV.

The major hazard of distal HFJV is barotrauma. Great caution must be exerted by the surgeon not to obstruct the surgical field. The high frequency jet ventilators which are now in use are equipped with electronic pressure transducers that can display endexpiratory airway pressure equipped with a shut-off mechanism.

Another hazard of this type of surgery is represented by the presence of blood or secretions in front of the opened distal lumen of the trachea. The trachea is protected by the continuous gas flow which moves outwards. To further decrease the risk of blood aspiration, careful suction of blood or secretions is mandatory throughout the procedure.

In conclusion, HFJV through a small catheter seems to be a reliable and safe ventilation technique for laryngo-tracheal resections with end-to-end anastomosis. It allows the surgeon to work on an almost free surgical field and protects the distal tracheobronchial tree from aspiration of blood and secretions. For the anaesthetist, this technique provides an adequate gas exchange. However, the hazards of barotrauma must always be kept in mind and adequate airway pressure monitoring must always be present.

\section{References}

1 Monnier P, Savary M, Chapuis G. Partial cricoid resection with primary tracheal anastomosis for subglottic stenosis in infants and children. Laryngoscope 1993; 103: 1273-83.

2 Pearson FG, Brito-Filomeno L, Cooper JD. Experience with partial cricoid resection and thyrotracheal anastomosis. Ann Otol Rhinol Laryngol 1986; 95: 582-5.

TABLE II Haemodynamic and gas exchange data (mean \pm SD)

\begin{tabular}{lcccccccc}
\hline & \multicolumn{4}{c}{ Paediatric group $(n=10)$} & \multicolumn{3}{c}{ Adult group $(n=7)$} \\
& Heat rate & $M A P(m m H g)$ & $P_{2}(m m H g)$ & $P_{2}\left(m O_{2}(m m H g)\right.$ & Heart rate & $M A P(m m H g)$ & $P a O_{2}(m m H g)$ & $P a C O_{2}(m m H g)$ \\
\hline T1 & $103 \pm 15$ & $69 \pm 13$ & $438 \pm 51$ & $38.2 \pm 7.3$ & $56 \pm 5$ & $84 \pm 8$ & $330 \pm 111$ & $37.4 \pm 3.9$ \\
T2 & $102 \pm 14$ & $74 \pm 17$ & $333 \pm 98^{\dagger}$ & $35.2 \pm 5.5$ & $58 \pm 6$ & $80 \pm 9$ & $297 \pm 128$ & $46.3 \pm 9.9^{\star}$ \\
T3 & $104 \pm 19$ & $72 \pm 13$ & $299 \pm 113^{\dagger}$ & $39.8 \pm 9.2$ & $67 \pm 9$ & $81 \pm 6$ & $261 \pm 104$ & $46.6 \pm 9.7^{\star}$ \\
T4 & $104 \pm 22$ & $70 \pm 13$ & $328 \pm 75^{\dagger}$ & $41.6 \pm 6.4$ & $67 \pm 9$ & $88 \pm 9$ & $252 \pm 90$ & $40.6 \pm 5.9$ \\
\hline
\end{tabular}

${ }^{*} P<0.05$ and ${ }^{\dagger} P<0.01$ compared with Tl. MAP: mean arterial pressure; Tl: $30 \mathrm{~min}$ before High Frequency Jet Ventilation (HFJV); T2: 10 min after the beginning of HFJV; T3: 10 minutes before the end of the HFJV period and T4: 30 minutes after the reinstitution of conventional ventilation. 
3 Lee $P$, English ICW. Management of anaesthesia during trachcal resection. Anaesthesia 1974; 29: 305-6.

4 Ellis RH, Hinds CJ, Gadd LT. Management of anaesthesia during tracheal resection. Anaesthesia 1976; 31: 1076-80.

5 Eriksson I, Nilsson L-G, Nordström S. Sjöstrand U. High-frequency positive-pressure ventilation (HFPPV) during transthoracic resection of tracheal stenosis and during peroperative bronchoscopic examination. Acta Anacsthesiol Scand 1975; 19: 113-9.

6 El-Baz N, El-Ganzouri A, Gottschalk W, Jensik R. Onelung high-frequency pressure ventilation for sleeve pneumonectomy: an alternative technique. Anesth Analg 1981; 60: 683-6.

7 Giunta $F$, Chiaranda M, Manani G, Giron GP. Clinical uses of high frequency jet ventilation in anaesthesia. Br J Anaesth 1989; 63: S102-6.

8 Rogers RC, Gibbons J, Cosgrove J, Coppel DL. Highfrequency jet ventilation for tracheal surgery. Anaesthesia 1985; 40: 32-6.

9 Obara H, Maekawa N, Iwais, Tamamoto $T$, Marakawa $A$. Reconstruction of the trachea in children with tracheal stenosis by using jet ventilation. Anesthesiology 1988; 68: 441-3.

10 Schur MS, Maccioli GA, Azizkban RG, Wood RE. High-frequency jet ventilation in the management of congenital tracheal stenosis. Anesthesiology 1988; 68: 952-5. 